\title{
Analysis of effects of burning in grasslands with quantifying succession stages by life-history traits in Kirigamine, central Japan
}

\author{
Jun Kato* and Mihoko Kawakami \\ Kirigamine plant research group, c/o Kato, 1940 Iwamurada, Saku, Nagano 385-0022 Japan
}

\begin{abstract}
To quantitatively analyze the effects of burning, we conducted a vegetation survey in the grasslands in Kirigamine, central Japan. We classified each species into stages of succession based on the life-history traits of the species and defined the score of the species in each stand based on the classification. We weighted the scores with a $v$-value, the product of coverage and height in the quadrat, and summed them to calculate the index of dynamic status. With these indices, we were able to quantitatively compare the stands in the study area and discern minute differences between the stands with different lengths of restoration periods since the disturbance of burning. These indices correlated with the $v$-value of trees, suggesting that the disturbance of burning seemed to affect the trees in the stand. We then calculated the growth of the tree species Pinus densiflora to evaluate its contribution to the index of dynamic status.
\end{abstract}

Key words: Effects of prescribed burning, Grassland succession, Life-history trait, Quantitative analysis

\section{INTRODUCTION}

Disturbance to plant communities alters the species composition of the stands (Connell 1978, Petraitis et al. 1989). Stands without artificial disturbance would flourish in succession. However, it is difficult to conduct a vegetation survey in a stand without artificial disturbance. Assuming that ideal succession would proceed under circumstances without artificial disturbance, Numata (1961, 1969) proposed a degree of succession (DS) to quantitatively evaluate how plant succession would proceed. He studied the quantitative evaluation of the dynamic process of plant stands based on the life-history traits of constituent species, because he believed that differences among the life-history traits of constituent species would drive stand succession.

Numata (1962) applied his idea to propose an index of grassland conditions to diagnose the degree of grazing in grasslands. Subsequently, Nakamura et al. (2000) applied this idea and proposed a stand quality index to quantify the degree of disturbance caused by over-grazing in the grasslands of Inner Mongolia. However, when Numata (1961) gave scores to species based on the classification of their life-history traits, the number of his categories was only four: annual herb, perennial herb, shrub, and tree. Therefore, using the DS, we were not able to quantitatively separate minute differences between grassland stands with and without disturbances such as prescribed burning in the same stages. Moreover, it was difficult to discern small differences in the length of the restoration period since the prescribed burning.

Here, we propose a more detailed system for classifying the life-history traits of species that grow in Kirigamine semi-natural grasslands. Consequently, we were able to separate minute differences among the stands, thereby quantifying the status of grasslands. Our category system

\section{Open Access http://dx.doi.org/10.5141/ecoenv.2013.013}

This is an Open Access article distributed under the terms of the Creative Commons Attribution Non-Commercial License (http://creativecommons. org/licenses/by-nc/3.0/) which permits unrestricted non-commercial use, distribution, and reproduction in any medium, provided the original work is properly cited.
Received 09 January 2013, Accepted 30 January 2013

*Corresponding Author

E-mail: quercus@sweet.ocn.ne.jp

Tel: +81-90-1869-6674 
is based on field experiments of secondary succession conducted by Hayashi $(1977,1992,2003)$.

Hayashi concluded that an ideal succession consists of eight stages. When succession proceeds, the dominant species may subsequently be altered. Therefore, the number of alternations of the dominant species until climax is eight. He uses the word "stage" as follows. Following the initial denuding of the plot, the first dominant species gradually appears (the first stage). As succession proceeds, the first dominant species is gradually replaced by a second dominant species (the second stage). The third, fourth, fifth, sixth, seventh, and eighth species become dominant subsequently (the third, fourth, fifth, sixth, seventh and eighth stage, respectively). He predicted the years $\mathrm{Y}(i)$ from the initial denuding of the plot until the $i^{\text {th }}$ stage in an ideal succession as follows: $\mathrm{Y}(1)=1, \mathrm{Y}(2)=2$, $\mathrm{Y}(3)=4, \mathrm{Y}(4)=8, \mathrm{Y}(5)=16, \mathrm{Y}(6)=32, \mathrm{Y}(7)=64$, and $\mathrm{Y}(8)=128$.

We assigned a score to each species as follows. First, we ascertained the life-history traits of the relevant species. Second, we assigned these species to the appropriate stage after considering the coincidence of life-history traits. Third, we assigned a score to each species. This score is the value equivalent to $\mathrm{Y}(i)$.

To assign scores, we must determine the stages of succession to which the species belong. In this report, we determined the life-history traits of species by field observation and references. Consequently, we were able to reduce years of work related to determining the life-history traits of each species through our experiments. Therefore, we have been able to classify species in the stand into the eight stages of succession to assign scores.

\section{STUDY SITE AND METHODS}

\section{Study site}

The study site was on a gradual slope that was at least 1000 ha in width (Kurihara et al. 2002). The landscape was grasslands with Miscanthus sinensis as the dominant species. Until the 1960s, people living in that area collected grass for making compost and cattle food (Kurihara et al. 2002). The study site is situated south of Mt. Kurumayama $\left(36^{\circ} 6^{\prime} 11^{\prime \prime} \mathrm{N}, 138^{\circ} 11^{\prime} 49^{\prime \prime} \mathrm{E}, 1925 \mathrm{~m}\right.$ a.s.l.).

The mean annual temperature is $6.5^{\circ} \mathrm{C}$ and the mean annual precipitation is $1281 \mathrm{~mm}$. Kira's warmth index is $52^{\circ} \mathrm{C}$-month and the cold index is $-41^{\circ} \mathrm{C} \cdot$ month (KiNOA 2012). The soil is black humic soil originating from volcanic ash (Suzuki, personal communication).

\section{Treatments of study plots and methods}

The study plots consisted of five plots: A, B, C, D, and E. Study plots A, B, and C are situated within $1 \mathrm{~km}$ of each other. Study plot D is situated about $4 \mathrm{~km}$ east of Study plot $\mathrm{C}$ and Study plot $\mathrm{E}$ is about $4 \mathrm{~km}$ south of Study plot B. Study plots A, B, C, and D are situated at ca. $1600 \mathrm{~m}$ a.s.l. The local government of Suwa City and the landowners managed the times and places of the prescribed burning and tree cutting in Study plots A, B, and C. They conducted prescribed burning in spring 2005, 2006, 2007, and 2012 in Study plot A, which is ca. 7 ha wide. In 2012, we conducted vegetation surveys of the quadrats of Study plot A at the end of June (Subplot A1), July (Subplot A2), August (Subplot A3), and September (Subplot A4). Study plot B is ca. 12 ha wide. We divided Study plot B into Subplots B1 (ca. 6 ha) and B2 (ca. 6 ha), because the government and landowners conducted prescribed burning in Subplot B1 in spring 2008 and tree cutting in Subplot B2 in autumn 2008. Study plot C was ca. 6 ha wide and they conducted prescribed burning there in spring 2009. Study plot D consisted of Subplots D1 (ca. 2 ha), D2 (ca. 2 ha), D3 (ca. 1 ha), and D4 (ca. 2 ha). The landowners of D1 conducted prescribed burning in Subplot D1 in the spring of every year. Ski companies governed Subplots D2 and D3, so they conducted mowing without removing the mowed grass in Subplot D2 in the autumn of every year and tree cutting without removing the cut trees in Subplot D3 in the autumn of every year. We left Subplot D4 without treatment from 1967 to autumn 2012. In Study plot E, situated at ca. $1300 \mathrm{~m}$ a.s.l., Pinus densiflora forests surrounded the grassland with $M$. sinensis as a dominant species. Study plot E, which is as wide as ca. $1 \mathrm{ha}$, is situated within the grassland. The local government of Nagano Prefecture built enclosures to protect endangered insects in Study plot $\mathrm{E}$ so that they managed to survive the plant Hemerocallis vespertina. Enclosure 1 was ca. 0.3 ha and Enclosure 2 was ca. 0.06 ha. The government mowed and removed the mowed grass in June 2011 and June 2012 in Enclosure 1, where we set Subplot E1. We left Enclosure 2 without treatment, where we set Subplot E2. We set Subplot E3 outside the enclosures and left it untreated.

In each subplot, we arbitrarily placed $1 \mathrm{~m} \times 1 \mathrm{~m}$ quadrats so that the distance between the quadrats was greater that $5 \mathrm{~m}$ (Okutomi and Itow 1967). The numbers of quadrats we placed in each subplot were 10 in Subplot A, 12 in Subplot B1, 12 in Subplot B2, 11 in Subplot C, 17 in Subplot D1, 6 in Subplot D2, 4 in Subplot D3, 9 in Subplot D4, 6 in Subplot E1, 6 in Subplot E2, and 6 in Subplot E3. We measured the maximum height $(\mathrm{cm})$ and visually es- 
timated the coverage (\%) of the quadrats of every species growing in the quadrat and the total coverage (\%) of the quadrats. We conducted vegetation surveys of Study plots B, C, D, and E between the end of August and the end of September 2012. On 25 Sep 2012, we clipped the aboveground biomass of the constituent species in a $1 \mathrm{~m} \times 1 \mathrm{~m}$ quadrat near Study plot A and dried them for $48 \mathrm{~h}$ at $60^{\circ} \mathrm{C}$. On 22 and 29 Oct 2012, we measured the population density, height, and crown size of the $P$. densiflora seedlings in Subplot B2.

\section{Definition of index and calculation}

To quantify the dynamic status of each subplot, we defined the index of dynamic status (IDS) by

$$
\text { IDS }=\Sigma(y r \times \text { weight }),
$$

where $y r$ is a score given to the species. The score is equal to the year of the $i^{\text {th }}$ stage $Y(i)$. The stage is determined by the life-history traits of the species. Weight was defined as follows:

$$
\text { weight }=v \text {-value } /(\Sigma v \text {-value }) \text {. }
$$

The $v$-value is a product of coverage and height of the species in the stand and correlated with the above-ground biomass (Sada et al. 1999, Yiruhan et al. 2001, Kobayashi et al. 2003, Kawada et al. 2005). The indices showed the weighted sum of $y r$ of the constituent species so that larger values of the indices indicate later stages of succession.

We determined the $y r$ scores based on Hayashi's (2003) stages of secondary succession. For example, we assigned a score of one to species with life-history traits that coincided with those of the first-stage species (dominant species in the first year). Similarly, we assigned scores of two, four, eight, 16, 32, and 64 to species with life-history traits that coincided with those of the second, third, fourth, fifth, sixth, and seventh stages, respectively (see $y r$ in Table 1).

When we determined the stage that the concerned species belong to, we focused on the following life-history traits. Because the species of the first stage of an ideal succession is an annual herb that produces seed of the clitochore type, we focused on the life-history traits of annual herbs and the production of seeds of the clitochore type. Consequently, we classified species with life-history traits of annual herbs and the production of seeds of the clitochore type into species of the first stage of succession. Similarly, species that had life-history traits of biennial herbs and the production of seeds of the anemochore type were classified into the second stage of succession.
Species of the third and fourth stages are both perennial herbs, but those of the third stage have elongated rhizomes and those of the fourth stage form tussocks. Growth form tufts are strongly related with the life-history trait of making tussocks (Shimizu 2001). Consequently, we assigned species with perennial herbs and growth form tufts to the fourth stage. In Nemoto's study (2006), almost all species of the fourth stage consisted of species with growth form tufts and perennial herbs. Growth form tufts occurred mainly in Poaceae and Cyperaceae (Tsutida and Suganuma 1978, Shimizu 2001).

Salix bakko (dormancy form M: microphanerophyte; dwarf trees $3-8 \mathrm{~m}$ in height) belongs to the fifth stage (dominant in the 16th year) (Hayashi 2003), so that we assigned a score of 16 to $y r$ of species with dormancy forms $\mathrm{M}$ and $\mathrm{N}$ (nanophanerophytes; shrubs $0.3-3 \mathrm{~m}$ in height). Similarly, we assigned a score of 32 to $y r$ of species with dormancy form MM (mesophanerophytes; large trees $>8 \mathrm{~m}$ in height) and the life-history trait of production of seeds of the anemochore type, which belongs to the sixth stage. Furthermore, Quercus mongolica ssp. crispula, which produces seeds of the clitochore type belongs to the seventh stage, so we assigned a score of 64 to $y r$ of species with dormancy form MM and the production of seeds of the clitochore type.

When we determined species life-history traits such as dormancy form, disseminule form, growth form, and flowering period, we referred to Numata and Yoshizawa (1975), Numata (1990), Osada (1993), Shimizu (1997), Asano (2005), and Hoshino and Masaki (2011). We referred to Miyawaki et al. (1994) for dormancy forms N, M, and MM. Some species have multiple growth forms $\mathrm{Nu}$ mata 1957). Consequently, when we were not able to classify a species into a single stage, we assigned the score of the mean value between the corresponding two (e.g., if it was difficult to classify whether the score of a species was one or two, we gave 1.5).

\section{RESULTS}

The relation between $v$-value and above-ground dry weight of the herbs growing in the study area is approximated by

$$
\mathrm{dw}=0.053 \times \mathrm{vv}^{0.52},
$$

where $\mathrm{dw}$ is the above-ground dry weight ( $\mathrm{g}$ ) and $\mathrm{vv}$ is the $v$-value $\left(\mathrm{cm}^{3} / \mathrm{m}^{2}\right)$ (ANOVA, $\mathrm{F}_{1,4}=6.116, \mathrm{P}=0.069$ ).

Species compositions and their $v$-values are shown in Table 1. In almost all subplots, the $v$-values of M. sinen- 


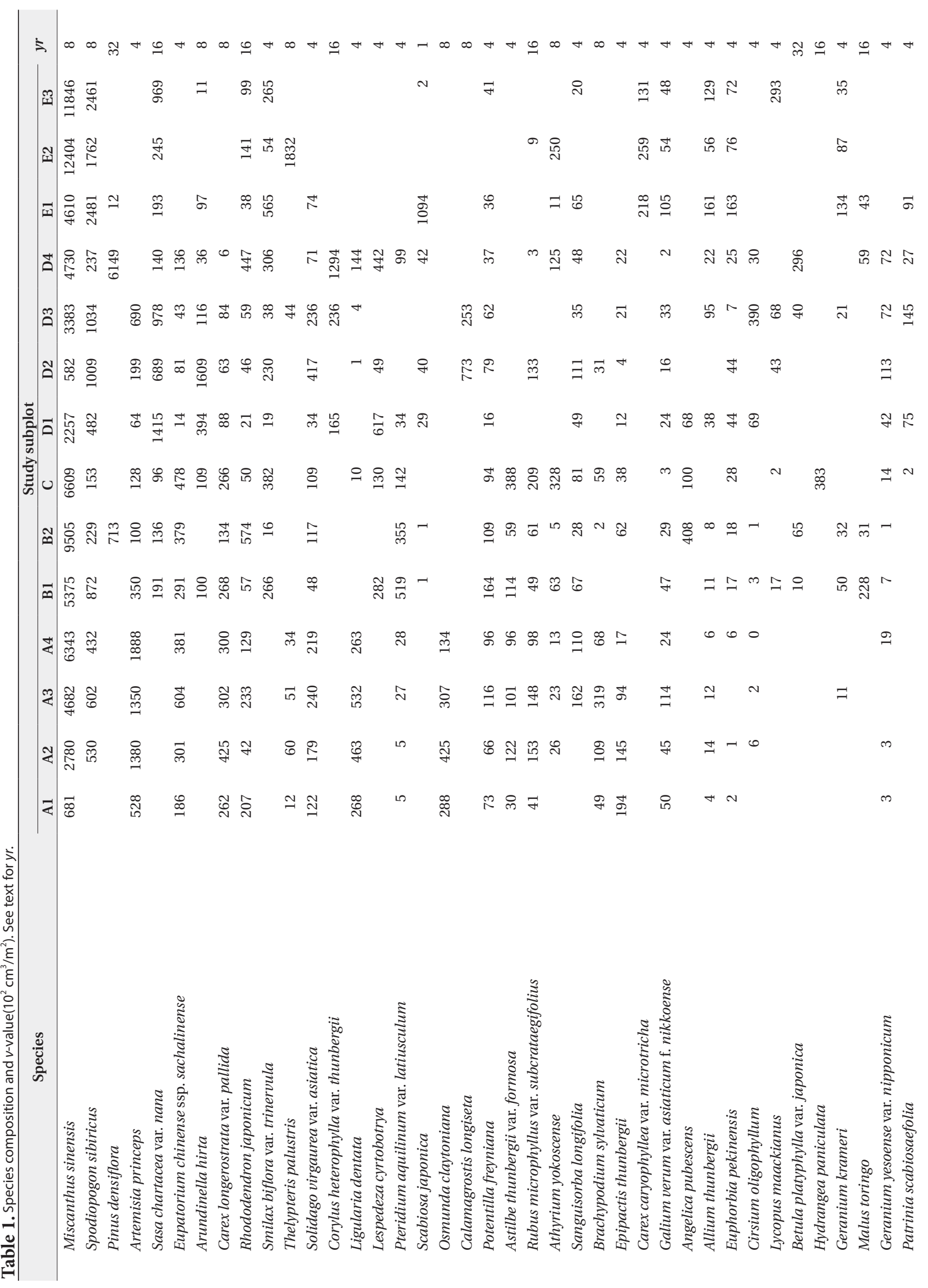




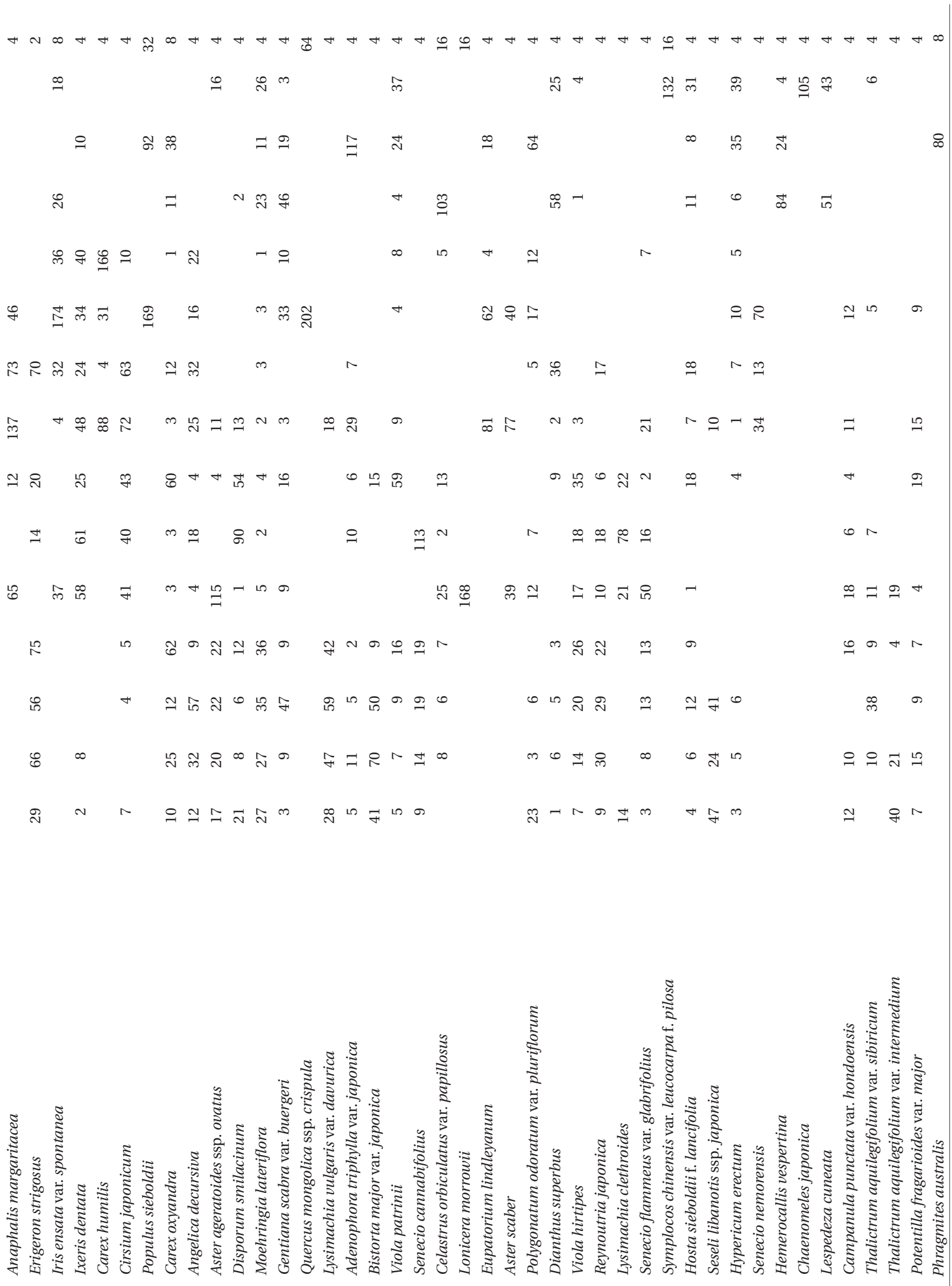




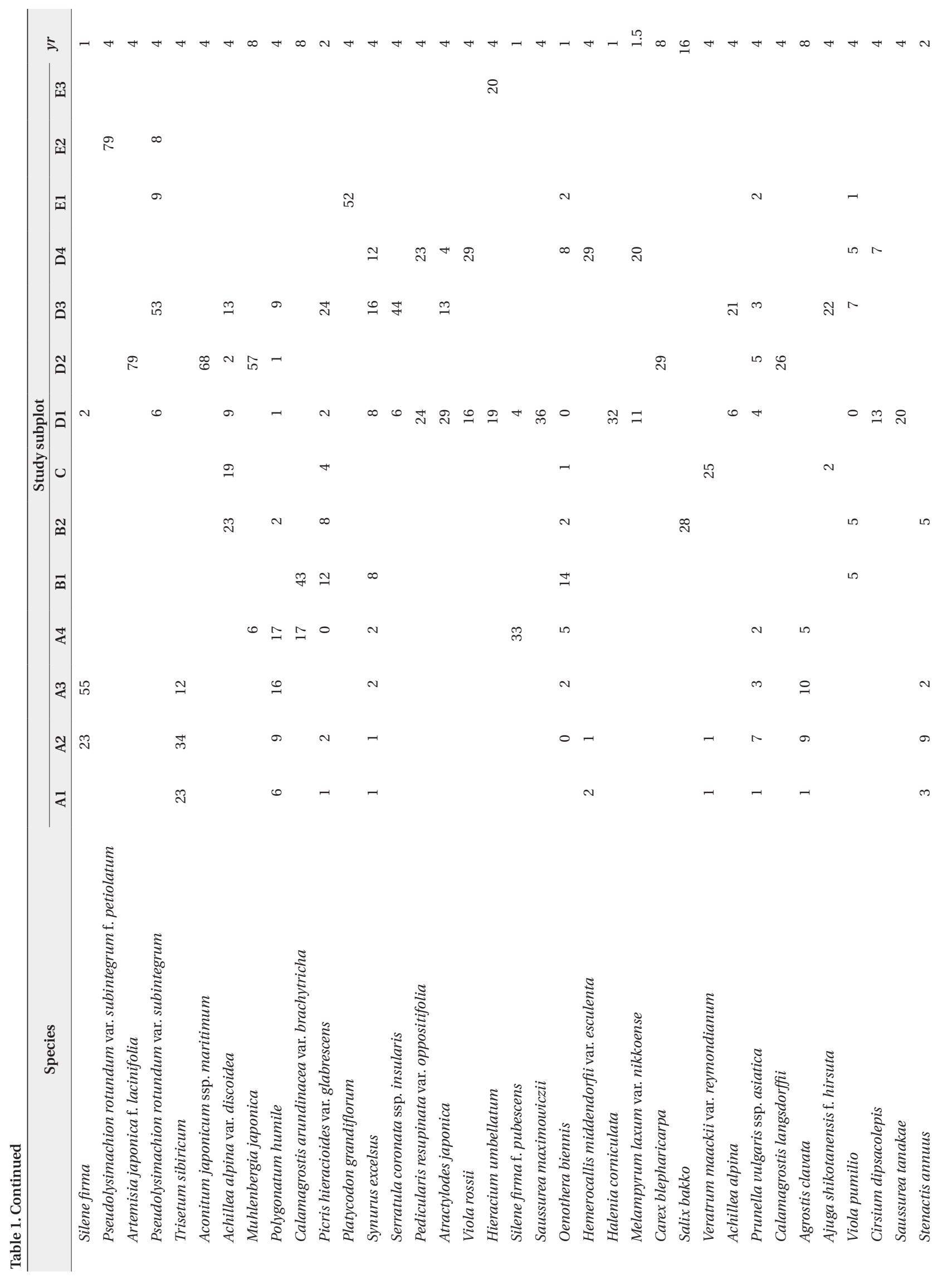



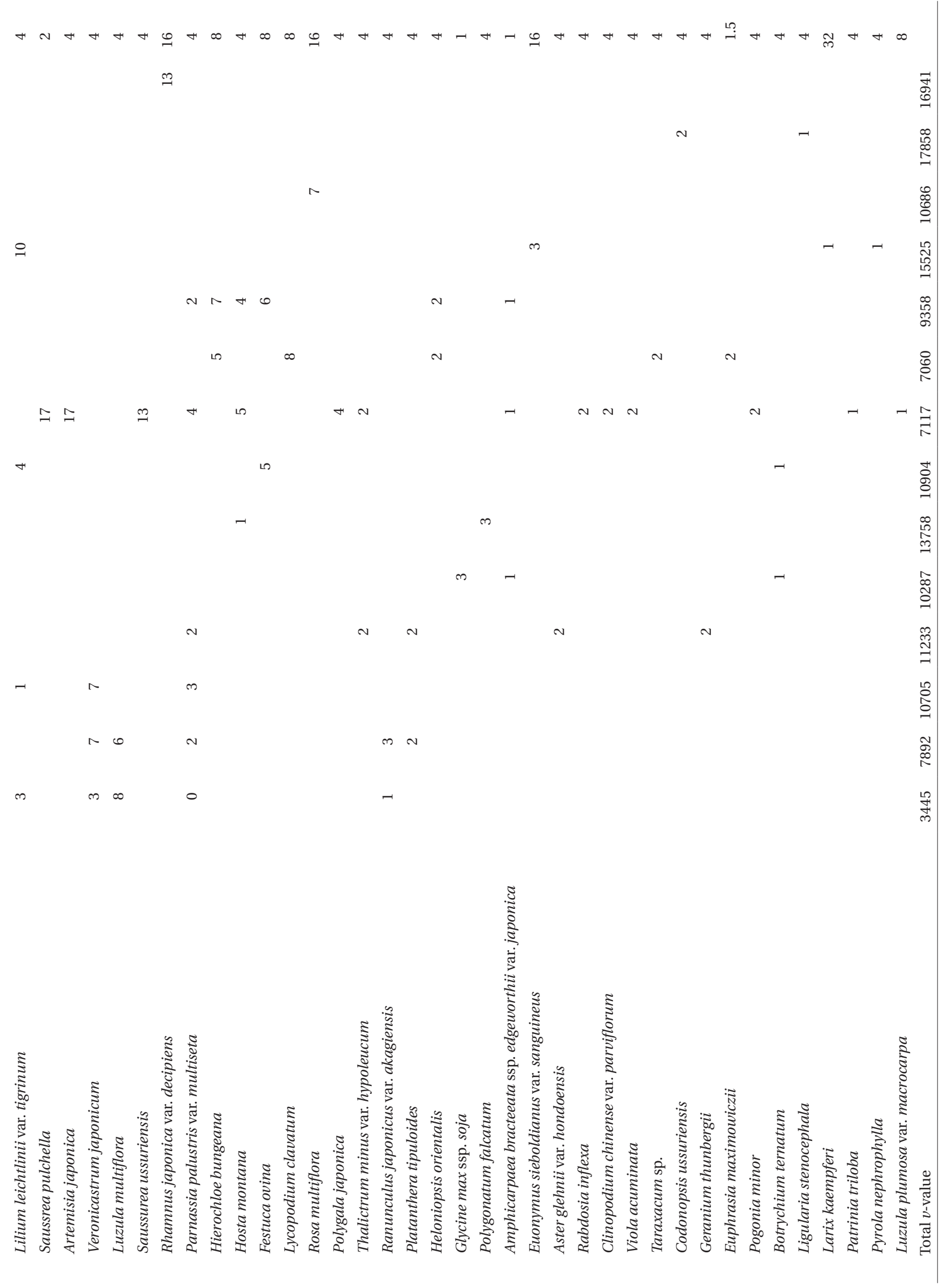


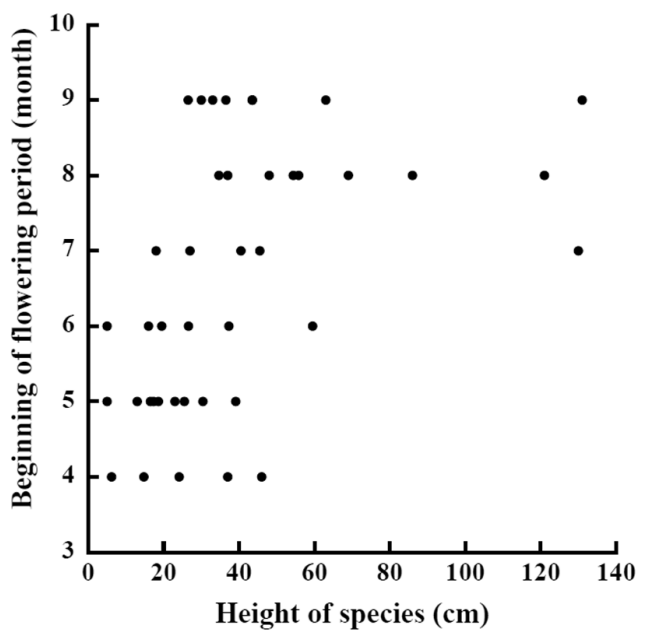

Fig. 1. Relation between the beginning of the flowering period and the height of the species in Subplot D4.

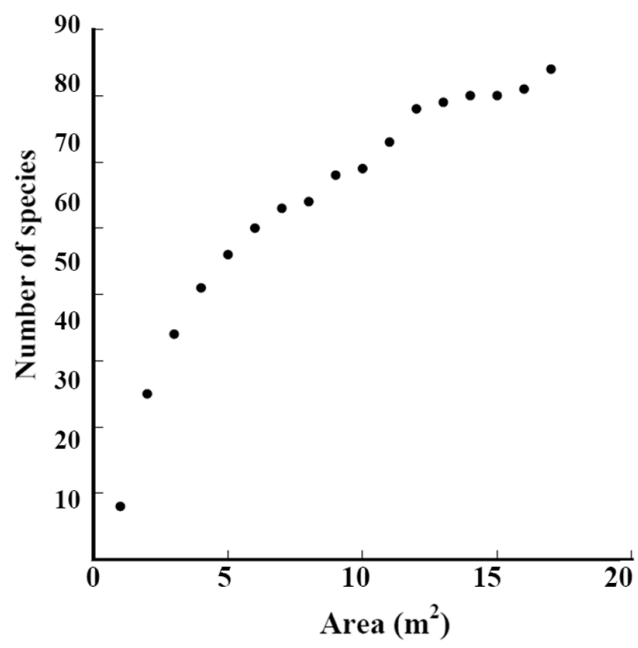

Fig. 2. Species-area curve in Subplot D1

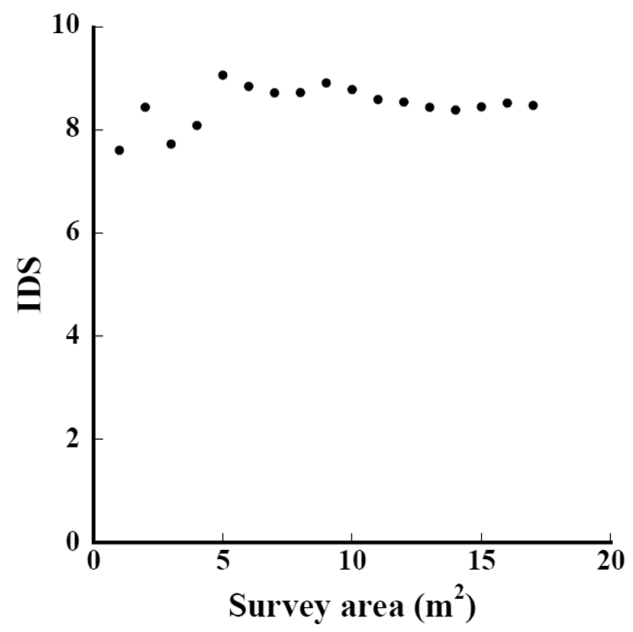

Fig. 3. Relation between indices and survey area in Subplot D1. sis were the largest among the constituent species. The sum of the $v$-values of constituent species in Subplots A1, A2, A3, and A4 gradually increased. The relation between the beginning of the flowering period and the height of species in Subplot D4 is shown in Fig. 1. We were able to divide the species into two groups: Group 1 contained earlier flowering and smaller height species and Group 2 contained later flowering and taller species. Smaller species tended to flower before the elongation of taller species.

The species-area curve of Subplot D1 is shown in Fig. 2. The total number of species continued increasing in the $17 \mathrm{~m}^{2}$ area. We should survey a wider area to record all growing species.

The relation between the indices and survey area in Subplot D1 is shown in Fig. 3. When the survey area was $17 \mathrm{~m}^{2}$, the IDS was 8.5. Even when the survey area was $1 \mathrm{~m}^{2}$, the IDS was within $\pm 10 \%$ of the value 8.5 . Furthermore, when the survey area exceeded $6 \mathrm{~m}^{2}$ and $11 \mathrm{~m}^{2}$, IDS converged was within $\pm 5 \%$ and $\pm 1 \%$, respectively. The IDS converges into a value at smaller areas than the area needed when the number of species converges.

The IDS in Subplot A1 was 6.4, Subplot A2 was 6.5, Subplot A3 was 6.8, and Subplot A4 was 6.9. We conducted vegetation surveys in Subplot A1 2 months after the prescribed burning, in Subplot A2 3 months after burning, in Subplot A3 4 months after burning, and in Subplot A4 5 months after burning. The indices gradually increased in the growing season. The indices were 7.5 in Subplot B1 and 7.6 in Study plot C. We conducted vegetation surveys in Subplots B1 4 years after prescribed burning and in Study plot C 3 years after burning. The indices were larger than those of plots within a year after the prescribed burning. The IDS of Subplot B2 was 9.2. The IDS was 8.5 in Subplot D1, 7.8 in Subplot D2, 9.7 in Subplot D3, and 18.5 in Subplot D4. The IDS was 6.9 in Subplot E1, 8.1 in Subplot E2, and 8.2 in Subplot E3.

The relation between the sum of the $v$-values of the trees and the IDS was approximated by

$$
\text { IDS_t }=0.000014 \times v \text {-value_t }+6.5272 \text {, }
$$

where IDS_t is the IDS of the subplots in this study and $v$-value_t is the sum of the $v$-values $\left(\mathrm{cm}^{3} / \mathrm{m}^{2}\right)$ in each subplot (Fig. 4.) (ANOVA, $\mathrm{F}_{1,12}=601, \mathrm{P}=1.3 \times 10^{-11}, \mathrm{R}^{2}=0.9824$ ). The indices were significantly correlated with the $v$-value of the trees.

The relation between the $v$-values of dwarf bamboo (Sasa chartacea var. nana) and those of trees other than dwarf bamboo is shown in Fig. 5. The trees other than dwarf bamboo did not grow in the place where dwarf 


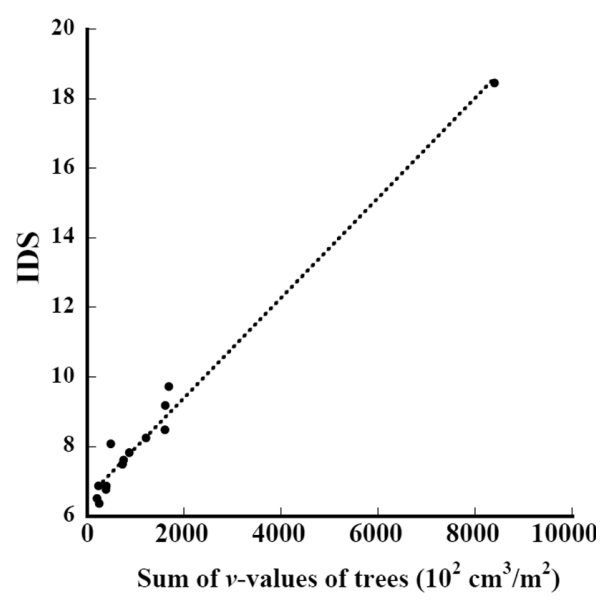

Fig. 4. Relation between the sum of $v$-values of trees and indices.

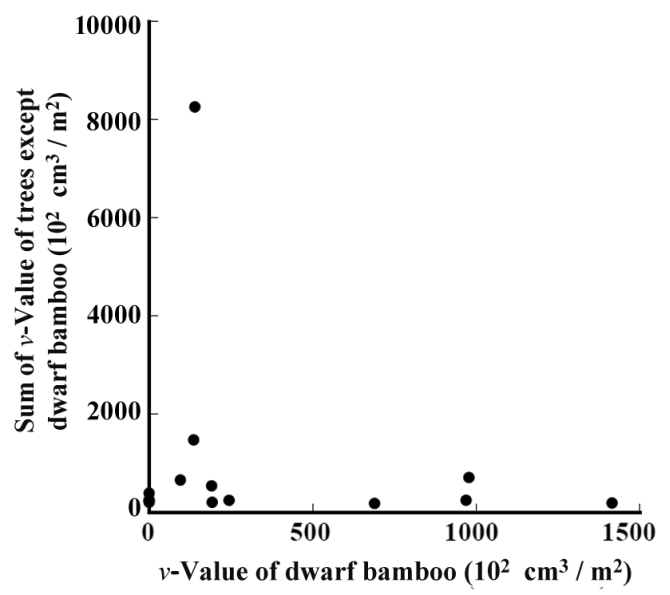

Fig. 5. Relation between the $v$-value of dwarf bamboo and the summed $v$-value of trees other than dwarf bamboo.

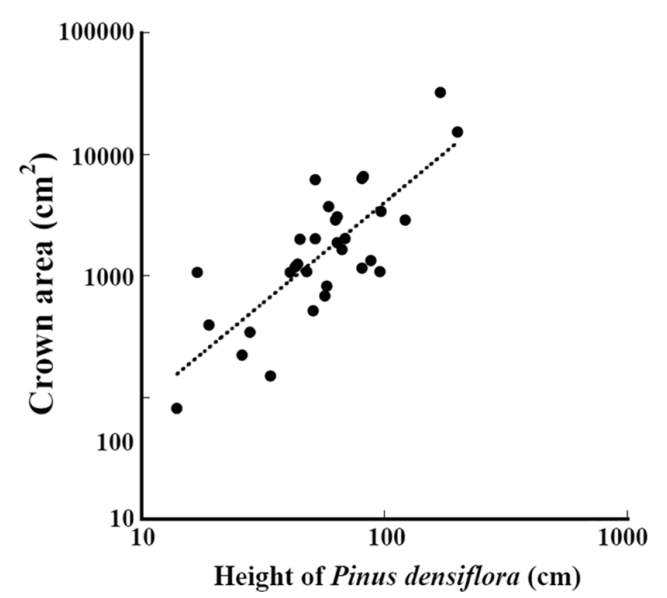

Fig. 6. Relation between the height of Pinus densiflora seedlings and their crown area.

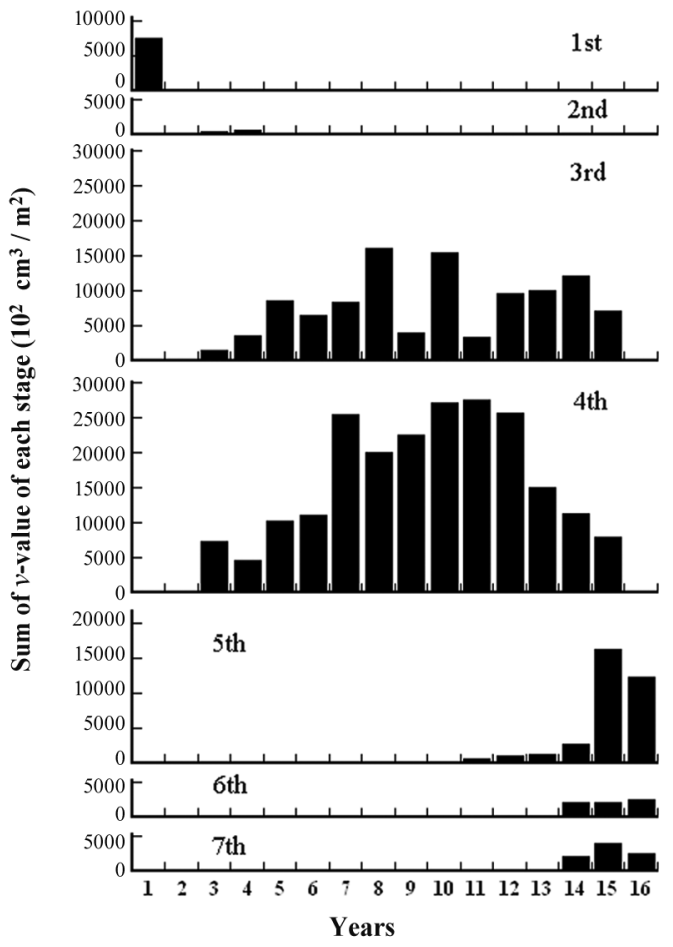

Fig. 7. Alternation of stages and the $v$-value of their species

bamboo grew. Among the percentages of $v$-value of trees other than dwarf bamboo, larger values were that of $P$. densiflora (33\%) and Rhododendron japonicum (22\%).

The relation between the height of $P$. densiflora seedlings and their crown area was approximated by

$$
\text { crown_a }=2.00 \times \text { height_p } \mathrm{p}^{1.65},
$$

where crown_a is the crown area $\left(\mathrm{cm}^{2}\right)$ and height_p is the height (cm) (Fig. 6) (ANOVA, $F_{1,29}=11.5, P=0.0019$ ). The crown area was significantly correlated with the height.

The number of $P$. densiflora seedlings growing in a 30$\mathrm{m}^{2}$ area was $13\left(0.43\right.$ individual $\left./ \mathrm{m}^{2}\right)$.

\section{DISCUSSION}

Iijima and Sado (2005) conducted experiments on secondary succession for 16 years after they denuded the area. We calculated the $v$-values of the constituent species and indices using data on height and coverage in their report. The dominant species subsequently changed (Fig.7). The relation between the years since they denuded the area and the indices was approximated by

$$
\text { IDS_i }=0.96 \times \text { year_L }+0.355 \text {, }
$$




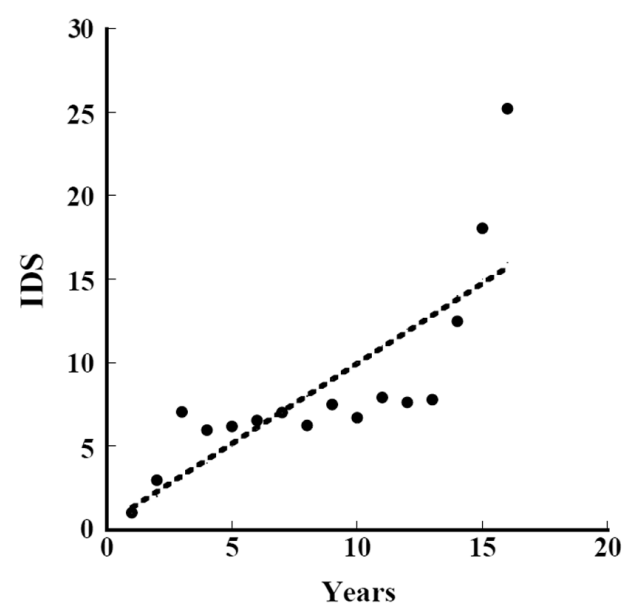

Fig. 8. Relation between years since the denudation of the area and indices.

where IDS_i is the value of the IDS by Iijima and Sago's data and year_L is the years since they started the experiment from the denuded area (Fig. 8) (ANOVA, $\mathrm{F}_{1,14}=22.97$, $\mathrm{P}=0.000286$ ). The indices were significantly correlated with the length of years in secondary succession since they denuded the area. The increment of change in the IDS per year was 0.96 .

According to Prach (1990), Glechoma hederacea, a Lamiaceae perennial herb with long, aerial runners or stolons (Birch and Hutchings 1999), became dominant at about the fifth year in the mesic sere of Bohemia, Czech. Furthermore, he reported that Arrhenatherum elatius, a tussock-forming Poaceae perennial species (Pfitzenmeyer 1962), became dominant at about the 15th year and that Prunus spinosa, a European shrub, became dominant at about the 25th year. Dölle et al. (2008) reported that the stages of annual herbs, perennial grasslands, shrubs, and pioneer forests were the periods of 1st-2nd years, 3rd-8th years, 10th-14th years, and after about 20 years of succession up to now, respectively, in Germany. Collins and Adams (1983) reported that in the area where they plowed once, the percentage coverage of forbs and grasses peaked in the first and tenth years in Oklahoma. We need modifications in years and categories to apply the IDS to other areas.

Kawakami et al. (personal communication) conducted vegetation surveys for 4 years between 2008 and 2011 in the same study area as ours and set a total of $1791 \mathrm{~m} \times 1 \mathrm{~m}$ quadrats. We calculated indices using their data of height and coverage. The relation between the length of years of restoration since the prescribed burning and the indices of their study and ours was approximated by

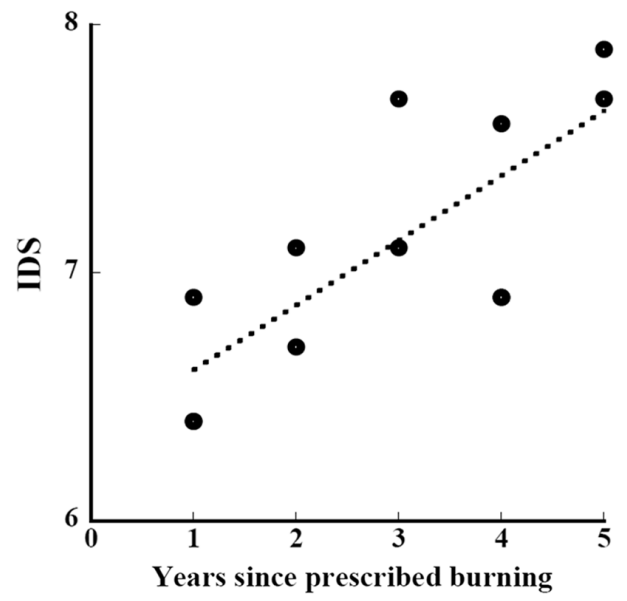

Fig. 9. Relation between the number of years of restoration since the prescribed burning and the indices of their study and ours.

$$
\text { IDS_b }=0.2612 \times \text { year_b }+6.3465 \text {, }
$$

where IDS_b is the IDS of the subplot and year_b is the years since the prescribed burning of the subplot (Fig. 9) (ANOVA, $\mathrm{F}_{1,10}=14.54, \mathrm{P}=0.0034$ ). The indices were significantly correlated with the length of years of restoration. The increment of the IDS in a year during the restoration period since the prescribed burning was 0.26 . The increment of 0.26 per year is as small as one-fourth of the aforementioned increment of 0.96 in succession without disturbance.

R. japonicum was able to sprout when its above-ground shoot was damaged (Nakano and Tsutida 2004). However, P. densiflora was not able to sprout once its above-ground shoot was damaged (Kato, personal communication). Therefore, when P. densiflora is damaged, it takes a few years to achieve seed dispersal, germination, and growth before it is renewed. Depletion of the sprouting ability in $P$. densiflora accounts for the slow restoration speed when prescribed burning in the grasslands was performed.

According to the reports of Negishi and Yagi (1985), Wu and Ando (2008), and Ogura (2009), the relation between the age and the height of the initial growing stage of $P$. densiflora is approximated by

$$
\text { height_pd }=3.43 \times \mathrm{y} \_\mathrm{p}^{1.81},
$$

where height_pd is the height $(\mathrm{cm})$ of $P$. densiflora in $\mathrm{y} \_\mathrm{p}$ years after germination (ANOVA, $\mathrm{F}_{1,13}=18.3, \mathrm{P}=0.00090$ ).

Because they conducted tree cutting in Subplot B2 in autumn 2008, the ages of $P$. densiflora seedlings growing in Subplot B2 were between 1 and 4 years old. Consequently, the mean number of $P$. densiflora seedlings were 3.25 individuals per year per $30 \mathrm{~m}^{2}\left(0.11\right.$ individual $\mathrm{m}^{-2}$ year $\left.^{-1}\right)$. 
Using Equations (5) and (8), we were able to estimate the volume, the product of the crown area and the height, of $P$. densiflora seedlings using the following equation:

$$
\text { vv_a }=52.41 \times \text { y_p } p^{4.80},
$$

where vv_a is the volume $\left(\mathrm{cm}^{3}\right)$ of $P$.densiflora in y_p years after germination.

Furthermore, with a mean annual establishment rate, 0.11 individuals $\mathrm{m}^{-2}$ year ${ }^{-1}$, we were able to estimate the increment of $v$-value of $P$. densiflora seedlings by

$$
\Delta \mathrm{vV}=5.76 \times \text { y_ } \mathrm{p}^{4.80},
$$

where $\Delta \mathrm{vv}$ is the increment of $v$-value of $P$. densiflora seedlings in a $1 \mathrm{~m} \times 1 \mathrm{~m}$ quadrat per year in y_p years after germination $\left(\mathrm{cm}^{3} \mathrm{~m}^{-2}\right.$ year $\left.{ }^{-1}\right)$.

Of the 14 subplots, the mean of the sum of $v$-values other than for P. densiflora was $1042100 \mathrm{~cm}^{3} / \mathrm{m}^{2}$ (SD=3775 $\left.\mathrm{cm}^{3} / \mathrm{m}^{2}, \mathrm{~N}=14\right)$. Therefore, the contribution by $P$. densiflora seedlings to the IDS in $n$ years after germination is estimated by

$$
\Delta \operatorname{IDS}(n)=32 \times\left\{\left(\sum_{\mathrm{y}_{-} \mathrm{p}=1}^{n} \Delta \mathrm{vv}\right) /\left(1042100+\sum_{\mathrm{y}_{-} \mathrm{p}=1}^{n} \Delta \mathrm{vv}\right)\right\}
$$

where, $\Delta \operatorname{IDS}(n)$ is the contribution by $P$. densiflora seedlings to the IDS in $n$ years after germination and $\Delta \mathrm{vv}$ is defined in Equation (10).

With Equations (10) and (11), we were able to estimate $\Delta$ IDS (5), which is the contribution by $P$. densiflora seedlings to the IDS 5 years after germination, as 0.54 (0.11 / year). Consequently, of the aforementioned annual increment of 0.26 in the IDS during the restoration period since prescribed burning, 0.11 (42\%) was contributed by P. densiflora seedlings.

\section{CONCLUSION}

We estimated the IDS of grasslands with the coverage and height of constituent species. Using the IDS, we quantitatively analyzed the effect of the disturbance of prescribed burning. Trees are affected by the disturbance of prescribed burning. We calculated, using the annual establishment and growth rates, the contribution by P. densiflora to restoration following the prescribed burning.

\section{LITERATURE CITED}

Asano S. 2005. Sadao Asano's biological flora of Japan. Zenkoku Noson Kyoiku Kyokai, Tokyo. (in Japanese)
Birch CPD, Hutchings MJ. 1999. Clonal segmentation-The development of physiological independence within stolons of Glechoma hederacea L. (Lamiaceae). Plant Ecol. 141: 21-31.

Collins SL, Adams DE. 1983. Succession in grasslands: thirtytwo years of change in a central Oklahoma tallgrass prairie. Vegetatio 51: 181-190.

Connell JH. 1978. Diversity in Tropical Rain Forests and Coral Reefs. Science 199: 1302-1310.

Dölle M, Bernhardt-Römermann M, Parth A, Schmidt W. 2008. Changes in life history trait composition during undisturbed old-field succession. Flora 203:508-522

Hayashi I. 1977. Secondary succession of herbaceous communities in Japan. Jap J Ecol 27: 191-200.

Hayashi I. 1992. Secondary succession of herbaceous communities in Japan: a case study in Sugadaira, Central Japan. Bull Sugadaira Montane Res Cen Tsukuba Univ 12: $1-12$.

Hayashi I. 2003. Plant ecology. Kokon Shoin, Tokyo. (in Japanese)

Hoshino T, Masami T. 2011. Illustated sedges of Japan. Heibonsha Tokyo. (in Japanese)

Iijima K, Sado R. 2005. Characteristics of the dominant species in secondary succession: A green area created using soil dressing in the campus on reclaimed land in Tokyo Bay. J Weed Sci Tech 50: 184-192. (in Japanese with English summary)

Kawada K, Vovk AG, Filatova OV, Araki M, Nakamura T, Hayashi I. 2005. Floristic composition and plant biomass production of steppe communities in the vicinity of Kharkiv, Ukraine. Grassl Sci 51: 205-213.

Kobayashi H, Nakamura Y, Watanabe Y. 2003. Analysis of weed vegetation of no-tillage upland fields based on the multiplied dominance ratio. Weed Biol Manage 3: 77-92.

Miyawaki A, Fujiwara M, Okuda S. 1994. Handbook of Japanese vegetation, revised edition. Shibundo, Tokyo. (in Japanese)

KiNOA. 2012. Mean temperature. http://nature2.jp/marsh/ avg.html. Accessed 19 Nov 2012.

Kurihara M, Nakano K, Kumada S, Furuya K. 2002. A study on the traditional land use and its decline on secondary grassland in Kirigamine. Env Infor Sci Extra Papers Env Infor Sci. 16: 115-120. (in Japanese)

Nakamura T, Go T, Wuyunna, Hayashi I. 2000. Effects of grazing on the floristic composition of grassland in Baiyinxile, Xilingole, Inner Mongolia. Grassl Sci 45: 342-350.

Nakano N, Tsutida K. 2004. Ecological studies of Rhododendoron japonicum (A.Gray) Suringar. and the depression effect of the growth by cutting in the Kirigamine 
Heights, Central Japan. Annal Env Sci Shinshu Univ 26: $22-32$. (in Japanese)

Negishi K, Yagi K. 1985. Diurnal and seasonal fluctuations in stem diameter of young Pinus densiflora and Chamaecyparis obtusa trees. Bull Tokyo Univ For 74: 149 - 164. (in Japanese with English summary)

Nemoto M. 2006. Zasso Gunraku No Dotai to Senni. In: Zasso Seitaigaku (Nemoto M, ed) Asakurashoten, Tokyo. pp $93-127$.

Numata M. 1957. Shokubutsu kiko to sono mondaiten. Seibutsukagaku 9: 3-11. (in Japanese)

Numata M. 1961. Seitai sen'i ni okeru mondaiten. Seibutukagaku 13: 146 - 152. (in Japanese)

Numata M. 1962. Sen'ido to jotaishisu niyoru sochishindan. Kagaku 32: 658 - 659. (in Japanese)

Numata M. 1969. Progressive and retrogressive gradient of grassland vegetation measured by degree of succession: ecological judgement of grassland condition and trend IV. Vegetatio 19: 96-127.

Numata M. 1990. The ecological encyclopedia of wild plants in Japan. Zenkoku Noson Kyoiku Kyokai, Tokyo. (in Japanese)

Numata M, Yoshizawa N. 1975. Weed flora of Japan illustrated by colour. Zenkoku Noson Kyoiku Kyokai, Tokyo. (in Japanese)

Ogura J. 2009. Recent growth of Pinus densiflora and Castanopsis cuspidate in the woods nearby Kyoto. J Kyoto Seika Univ 35: 143 - 162. (in Japanese with English abstract)

Okutomi K, Itow S. 1967. Shokusei no chousahou, bunsekiteki sokutei. In: Seitaigaku jisshusho (Seitaigaku Jisshukon'dankai, ed). Asakura Shoten, Tokyo, pp 50-68. (in Japanese)

Osada T. 1993. Illustrated grasses of Japan, enlarged ed. Heibonsha, Tokyo.

Petraitis PS, Latham RE, Niesenbaum RA. 1989. The Maintenance of Species Diversity by Disturbance. Q Rev Biol 64: 393-418.

Pfitzenmeyer CDC. 1962. Arrhenatherum Elatius (L.) J. \&. C. Presl (A. Avenaceum Beauv.). J Ecol 50: 235-245.

Prach K. 1990. Plant population. In: Succession in abandoned fields. Studies in Central Bohemia, Czechoslovakia. (Osbornová J, Kovářová M, Lepš J, Prach K, eds) Kluwer Academic Pub, Dordrecht, pp 23-29.

Sada Y, Miura R, Ito M. 1999. Weed biomass estimation based on plant coverage and height. J Weed Sci Tech 44:106-107. (in Japanese)

Shimizu T. 1997. Flora of Nagano Prefecture. Shinano Mainichi Shimbunsha, Nagano. (in Japanese)

Shimizu T. 2001. Zusetsu Shokubutsu Yogo Jiten. Yasakashobo, Tokyo. (in Japanese)

Tsutida K, Suganuma T. 1978. Seikatukei Sosei. In: Sochi Chosaho Handbook. (Numata M, ed). Tokyo Univ Press, Tokyo, pp 21 - 24. (in Japanese)

Yiruhan, Hayashi I, Nakamura T, Shiyomi M. 2001. Changes in floristic composition of grasslands according to grazing intensity in inner Mongolia, China. Grassl Sci. 47: 362-369.

Wu CP, Ando M. 2008. Effects of different ground treatments on the establishment and growth of Pinus densiflora seedlings on Daimonji-yama Mountain, Kyoto, Japan. J Jpn Soc Reveget Tech. 34: 623-630. (in Japanese with English abstract) 